\title{
There is No Cryptococcal Antigenaemia among A Cohort of Children with Advanced HIV Infection in an Antiretroviral Therapy Programme in Makurdi, Nigeria
}

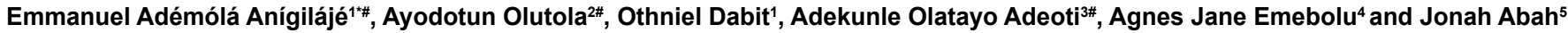

${ }^{1}$ Department of Paediatrics, Benue State University, Makurdi, Benue State, Nigeria

${ }^{2}$ Centre for Clinical Care and Clinical Research, 29 Mambilla Street, Off Aso Drive, Maitama, Abuja, Nigeria

${ }^{3}$ Department of Medicine, Ekiti State University Teaching Hospital, Ado-Ekiti, Ekiti State, Nigeria

${ }^{4}$ Department of Paediatrics, Federal Medical Centre, Makurdi, Benue State, Nigeria

${ }^{5}$ Department of Family Medicine, Federal Medical Centre, Makurdi, Benue State, Nigeria

\#Contributed equally and shared first Authorship

\begin{abstract}
Introduction: Cryptococcal disease is an important opportunistic infection and a major contributor to mortality in HIVIAIDS. Unfortunately, there has been no data describing the burden of cryptococcosis in Nigerian HIV-infected children.

Methods: A cross-sectional study between January 2013 to September 2013 at the Federal Medical Centre, Makurdi to determine the prevalence and risk factors of cryptococcal antigenaemia among a cohort of consecutive HIV-infected children ( $\leq 15$ years of age) with a CD4 count of $\leq 200$ cells $/ \mathrm{mm} 3$, including treatment-naive and those on Antiretroviral Therapy (ART). The cryptococcal antigen Lateral Flow Assay method was used twice on each sample collected from the children.

Results: A total of 699 children were seen but only 88 children had CD 4 count of $\leq 200 \mathrm{cell} / \mathrm{mm} 3$. These 88 subjects included 47 Males and 41 Females (M: F, 1:0.9). The age range was from 12-168 months with a mean of $73.23 \pm 41.06$ months. The CD4 count was from 10 to $198 \mathrm{cells} / \mathrm{mm} 3$ with a median of $104 \mathrm{cells} / \mathrm{mm} 3$ (Interquartile range, IQR; 53$157)$. Twenty $(20 / 88,22.7 \%)$ children had a CD4 count of less than 50 cells/mm3, $24(27.3 \%)$ had CD4 counts between 51-100, and 44 children (50\%) had CD4 counts between 101-198 cell/mm3. The median viral load was 3,016 copies/ $\mathrm{ml}$ with an IQR of 200-39,354 copies/ml. Only 11 (12.5\%) children were not on HAART. There was no cryptococcal antigenaemia $(0 \%)$ among the 88 children tested. Statistical analysis was thus limited to simple description.
\end{abstract}

Conclusion: In our setting, cryptococcosis may not be a strong consideration in the differential diagnosis of severely immunosuppressed HIV-infected children ( $\leq 15$ years of age) presenting with pneumonia and or meningoencephalitis.

Keywords: Cryptococcosis; HIV; Children; Severe immunosuppression

\section{Introduction}

Despite the availability and success of Highly Active Antiretroviral Therapy (HAART) in reducing mortality from AIDS, the late presentation of patients infected with HIV contributes to the mortality resulting from HIV-related opportunistic infections (OIs) [1,2]. Cryptococcal disease is one of the most important OIs, and a major contributor to this mortality [1,2]. In adult population, the case fatality rate in patients with cryptococcal meningitis (CM), remains unacceptably high, particularly in sub-Saharan Africa, at between 35\%$65 \%[3-5]$.

Whilst, some studies indicated that cryptococcosis may be uncommon among HIV-infected children [6-10], a South African survey reported an incidence of 47 cases per 100,000 HIV-infected children [11]. Unfortunately, there has been no data describing the burden of cryptococcosis in Nigerian HIV-infected children. Nevertheless, cryptococcosis must still be considered in the differential evaluation of a HIV-infected child presenting with meningoencephalitis, with diagnosis often necessitating the need to do Indian ink smear of the cerebrospinal fluid (CSF) and the need to wait for the fungal culture of the blood and the CSF.

Cryptococcal antigenaemia ( $\mathrm{Cr} \mathrm{Ag})$ is indicative of systemic disease [12]. It correlates with fungal burden [12] and is detectable in patients with CM and those with disseminated pulmonary cryptococcosis [13]. It is detectable at a median of 22 days before the onset of symptoms [14] and has been shown to be $100 \%$ sensitive in predicting the development of CM in the first year of antiretroviral therapy [15].

The World Health Organization (WHO) [2] in 2011 recommended that "Routine serum or plasma Cr Ag screening in ART-naive adults (but not adolescents or children), followed by pre-emptive anti-fungal therapy if $\mathrm{Cr} \mathrm{Ag}$ positive may be considered prior to ART initiation in patients with a CD4 count less than 100 cells $/ \mathrm{mm} 3$, and where this population also has a high prevalence of cryptococcal antigenaemia". Nevertheless, taking cognizance of the report of Meiring et al. [11] in South Africa, there may be a need for more countries in Sub-Saharan Africa to

*Corresponding author: Emmanuel Adémólá Anígilájé, Department of Paediatrics Benue State University, Makurdi, Benue State, Nigeria, Tel: +2348033833839; E-mail: demolaanigilaje@yahoo.co.uk

Received October 09, 2013; Accepted November 01, 2013; Published November 05, 2013

Citation: Anígilájé EA, Olutola A, Dabit O, Adeoti AO, Emebolu AJ, et al. (2013) There is No Cryptococcal Antigenaemia among A Cohort of Children with Advanced HIV Infection in an Antiretroviral Therapy Programme in Makurdi, Nigeria. J AIDS Clin Res 4: 261. doi: 10.4172/2155-6113.1000261

Copyright: @ 2013 Anígilájé EA, et al. This is an open-access article distributed under the terms of the Creative Commons Attribution License, which permits unrestricted use, distribution, and reproduction in any medium, provided the original author and source are credited. 
determine the burden of cryptococcosis in HIV-infected children.

However, the high cost and the unavailability of this rapid diagnostic tool remains a contending barrier in resource constrained countries like Nigeria. Regardful of this barrier, if the prevalence of cryptococcal antigenaemia among the children in our setting is high, it may be cost effective to identify these children for pre-emptive antifungal therapy and thus reduce the mortality from $\mathrm{CM}$.

We therefore carried out this study to determine the prevalence and risk factors of cryptococcal antigenaemia among a cohort of HIVinfected children with a CD4 count of $\leq 200$. This includes children on $\mathrm{ART}$ and those that are treatment naïve.

\section{Methods}

\section{Study area and setting}

This cross-sectional study was carried out among HIV-infected children receiving care and ART at the Paediatric ART Clinic of the Federal Medical Centre (FMC), Makurdi between January 2013 and September 2013. FMC, Makurdi, is the only tertiary health facility providing care and treatment for paediatric HIV in Benue State and, therefore, is a referral centre for primary and secondary health facilities in Benue State and the surrounding states of Taraba, Nasarawa, and Kogi.

\section{Ethical consideration}

Ethical approval for the study was obtained from the Hospital Research and Ethics Committee. Written consent of the parents or the caregivers and the assent of the child (if more than 7 years of age) were sought for and gotten for the study.

\section{Inclusion criteria for the study}

HIV infected children who are $\leq 15$ years of age with a CD 4 count of less than or equal to $200 \mathrm{cell} / \mathrm{mm} 3$ at the time of $\mathrm{Cr} \mathrm{Ag}$ assay (or in the previous 3-month). This includes children who had been on HAART or those that are ART-naïve. Adolescent children who are more than 15 years routinely receive care and treatment at the Adults' ART clinic of FMC, Makurdi and were thus excluded from the study.

\section{Follow-up of subjects, operational definitions, recruitments into study and data collection}

FMC, Makurdi provides paediatric HIV care and treatment in accordance with the Nigerian Guidelines on Paediatric HIV/AIDS Treatment and Care.

Consecutive children (both treatment naive and those on HAART) at the follow-up ART clinic who were having a CD4 Count of $\leq 200$ cells/mm 3 between January 2013 and September 2013 were considered for the study. HIV infected treatment-naive children were defined as HIV infected children who had received no prior antiretroviral drugs, except for prevention of mother-to-child transmission (PMTCT). First line HAART regimen consisted of either Zidovudine (AZT) or Stavudine (D4T) plus Lamivudine (3TC) plus either Nevirapine (NVP) or Efavirenz (EFZ) or Lopinivir/ritonivir-LPV/r (for those with prior exposure to NVP through PMTCT). Children failing on treatment were placed on second line HAART of Abacavir (ABC) plus 3TC plus LPV/r. Didanosine (ddI) is substituted for $\mathrm{LPV} / \mathrm{r}$ if it is a component of the first line HAART.

Treatment failures were considered in children who had received HAART for at least 24 weeks, with ensured adherence to therapy and adequate nutrition. Viralogical failure was defined as the HIV RNA becoming reproducibly detectable again after being "undetectable" (HIV RNA PCR $<200$ copies/ml) or HIV RNA not suppressed to undetectable levels after 6 months of therapy or a significant and reproducible increase in HIV RNA (viral load rebounds by at least 0.5 $\log 10)$ after substantial response. Immunological failure was defined as the return in $\mathrm{CD} 4 \%$ to pre-therapy baseline or below, in the absence of other concurrent infection to explain the transient CD4 decrease or a greater than $50 \%$ fall from peak levels of therapy of CD4 cell percentage in the absence of other concurrent infection to explain the transient CD4 decrease. Clinical failure was defined as lack of growth among children who show an initial response to treatment, or a decline in growth among children who show an initial growth response to therapy or a loss of neuro-developmental milestones or development of encephalopathy or occurrence of new opportunistic infection or malignancy signifying clinical disease progression or recurrence of prior opportunistic infections, such as oral candidiasis that was refractory to treatment.

Electronic data of the children on our care and treatment were analysed prior to January 2013 and those with current CD4 count of $\leq 200$ cells $/ \mathrm{mm} 3$ (or in the last 3-months) were identified and their enrolment Identification number noted. They were then recruited for the study at consecutive scheduled follow-up clinic. Scheduled followup clinic, were as follows, every month for the first 3-months, every 3-months for one year and subsequently every 6-month Children that were newly recruited into care and treatment were also eligible for study if they were having CD4 count of $\leq 200$ cells $/ \mathrm{mm} 3$.

A structured study proforma was developed and administered to capture socio-demographic and a priori risk factors [16-18] of cryptococcosis among the children included for the study. The corresponding Author solely administered the study proforma. For historical risk factors for cryptococcosis, electronic record data were also analysed to complement the verbally recollected information. Relevant information thus obtained include possible mode of HIV acquisition, the CD4 count, the WHO Clinical Stage, the viral load, steroid use, fluconazole use, whether or not the subjects help their parent in farming (defined as keeping of pigeons/poultry at home/tendering of fruits and vegetables), family members smoking cigarette, blood transfusions, prior history of cryptococcosis, current or prior history of other opportunistic infections and symptoms and signs suggestive of meningitis. Chronic diarrhoea defined as persistent diarrhoea 14 days or more. Recurrent sepsis defined as two or more episodes in previous six months.

\section{Method of cryptococcal antigen assay}

About $5 \mathrm{mls}$ of blood was collected from each subject. All the samples were tested in the APIN/PEPFAR laboratory of the FMC, Makurdi. The cryptococcal antigen Lateral Flow (Cr Ag-LF) Assay method was employed. All the instructions regarding the handling, the storage, the validity and the procedure of the test were observed as stipulated by the manufacturer [19]. Tests were performed twice on each sample. The collected blood was spurned to harvest the plasma. If a delay is encountered, specimens were stored at $4^{\circ} \mathrm{C}$ for a maximum of 72 hours. The test kit is from Immuno-Mycologics Inc., 2700 Technology Place, Norman OK 73071, USA, Reference CR2003, Lot 012CR2. When compared to the gold standard diagnoses of cryptococcosis (culture and/or Indian ink), the test has a sensitivity and specificity of $100 \%$ for serum antigen, $98.9 \%$ and $100 \%$ for plasma antigen and $100 \%$ sensitivity and specificity for CSF antigen. 


\section{Data analysis}

Characteristics were summarized using medians for continuous variables and proportions for categorical variables. Since there was no cryptococcal antigenaemia, univariate and multivariate logistic regression analyses were not performed to assess risk factors.

\section{Results}

A total of 699 children were seen between January 2013 and September 2013, but only 88 children satisfied the inclusion criteria. Table 1 shows that of the total of 88 children, 47 were Males and 41 were Females (M: F, 1:0.9). The age range was from 12-168 months with a mean of $73.23 \pm$ 41.06 months. A majority of the subjects, $(60.2 \%)$ was between the ages of 6-12 years. More than half of the subjects (55.75\%) were in WHO Stage 1 , followed by Stage 3 (21.6\%). The CD4 count range is from 10 to198 cells/ $\mathrm{mm} 3$ with a median of 104 and Interquartile range (IQR) of 53-157 cells/ $\mathrm{mm} 3$. The proportions of the CD4 counts were as shown in Table 1 . The median viral load was 3,016 copies/ml and IQR of 200-39,354 copies $/ \mathrm{ml}$.
Almost one-third (28.4\%) of the subjects had undetectable viral load. 11 subjects were not on HAART. Half of the study population was on first line HAART of AZT/3TC/NVP. Seventeen (19.3\%) subjects were on 2nd line HAART of $\mathrm{ABC} / 3 \mathrm{TC} / \mathrm{LPVr}$.

Table 2 shows that a vast majority acquired HIV infection via Mother to Child Transmission (MTCT) and more than 2/3rd also engaged in farming. Also, the substantive risk factors for cryptococcosis in the cohort included: exposure to farming experience; past history of opportunistic infections of chronic diarrhoea; pulmonary tuberculosis pneumonia; and an on-going treatment for pulmonary tuberculosis.

\section{Discussion}

To the best of the Authors' knowledge, this is the first study that determines the prevalence of cryptococcal antigenaemia among Nigerian children with advanced HIV-infection. However, the $0 \%$ prevalence among the 88 children surveyed may support the 2011 WHO recommendation which excluded adolescent and children from

\begin{tabular}{|l|l|}
\hline Characteristics & $\mathrm{N}(\%)$ \\
\hline Age group (years) & $11(12.5)$ \\
\hline$<1$ & $20(22.7)$ \\
\hline $1-5$ & $53(60.2)$ \\
\hline $6-12$ & $4(4.6)$ \\
\hline$>12$ & $72.23 \pm 41.06$ \\
\hline Mean age in months (SD) & \\
\hline Gender & $47(53.4)$ \\
\hline Male & $41(46.6)$ \\
\hline Female & \\
\hline WHO Stage & $49(55.7)$ \\
\hline 1 & $14(15.9)$ \\
\hline 2 & $19(21.6)$ \\
\hline 3 & $6(6.8)$ \\
\hline 4 & \\
\hline CD4Count & $104(53-157)$ \\
\hline Median (IQR) & $20(22.7)$ \\
\hline$<50$ & $24(27.3)$ \\
\hline $51-100$ & $44(50.0)$ \\
\hline $101-198$ & \\
\hline Viral Load & $3016(200-39,354)$ \\
\hline Median (IQR) & $31(35.2)$ \\
\hline$\leq 1000$ & $24(27.3)$ \\
\hline $1001-10,000$ & $22(25.0)$ \\
\hline $10,001-100,000$ & $11(12.5)$ \\
\hline$>100,000$ & $63(71.6)$ \\
\hline Detectable & $25(28.4)$ \\
\hline Undetectable & \\
\hline On HAART & $77(87.5)$ \\
\hline Yes & $11(12.5)$ \\
\hline No & $5(5.7)$ \\
\hline Types of HAART & $44(50.0)$ \\
\hline AZT/3TC/LPVr & $8(9.1)$ \\
\hline AZT/3TC/NVP & $12(13.6)$ \\
\hline D4T/3TC/NVP & $2(2.3)$ \\
\hline AZT/3TC/EFV & $17(19.3)$ \\
\hline ABC/3TC/EFV & \\
\hline ABC/3TC/LPVr & \\
\hline Age & \\
\hline
\end{tabular}

Age range is $12-168$ months, CD4 count range is from 10 to 198 cells $/ \mathrm{mm} 3$, $\mathrm{SD}=$ Standard deviation, $I \mathrm{QR}=$ Interquartile range.

Table 1: Some demographic, clinical and Immunoviralogical characteristics of the

\begin{tabular}{|l|l|}
\hline Risk factors & $\mathrm{N}(\%)$ \\
\hline Farming & $69(78.4)$ \\
\hline Yes & $19(21.6)$ \\
\hline No & \\
\hline Family member smokes cigarette & \\
\hline Yes & $8(9.1)$ \\
\hline No & $80(90.9)$ \\
\hline Mode of HIV acquisition & \\
\hline MTCT & $82(93.2)$ \\
\hline Blood transfusion & $6(6.8)$ \\
\hline Sexual abuse ever & $-(0.0)$ \\
\hline Has received blood transfusion & \\
\hline Yes (number of times) & \\
\hline 1 & $10(11.4)$ \\
\hline 2 & $4(4.5)$ \\
\hline 3 & $4(4.5)$ \\
\hline 8 & $1(1.1)$ \\
\hline No & $69(78.5)$ \\
\hline History of opportunistic infection(s) & \\
\hline Herpes Zoster & \\
\hline Yes & $3(3.4)$ \\
\hline No & $85(96.6)$ \\
\hline Chronic diarrhoea & \\
\hline Yes & $35(39.8)$ \\
\hline No & $53(60.2)$ \\
\hline Oral thrush & \\
\hline Yes & $7(7.9)$ \\
\hline No & $81(92.1)$ \\
\hline Esophageal candidiasis & \\
\hline Yes & $4(4.5)$ \\
\hline No & $84(95.5)$ \\
\hline Pulmonary tuberculosis & \\
\hline Yes & $20(22.7)$ \\
\hline No & $68(77.3)$ \\
\hline Pneumonia & \\
\hline Yes & $17(19.3)$ \\
\hline No & $71(80.7)$ \\
\hline Recurrent sepsis & \\
\hline Yes & \\
\hline No & \\
\hline
\end{tabular}
subjects. 


\begin{tabular}{|l|l|}
\hline Steroid use & \\
\hline Yes & $1(1.1)$ \\
\hline No & $87(98.9)$ \\
\hline Current opportunistic infection(s) & \\
\hline Herpes zoster & $0(0.0)$ \\
\hline Yes & $88(100.0)$ \\
\hline No & \\
\hline Chronic diarrhea & \\
\hline Yes & $5(5.7)$ \\
\hline No & $83(94.3)$ \\
\hline Oral thrush & \\
\hline Yes & $2(2.3)$ \\
\hline No & $86(97.7)$ \\
\hline Esophageal candidiasis & \\
\hline Yes & $2(2.3)$ \\
\hline No & $86(97.7)$ \\
\hline Fluconazole use( 3 month before study) & \\
\hline Yes & $2(2.3)$ \\
\hline No & $86(97.7)$ \\
\hline Pulmonary Tuberculosis & \\
\hline Yes & $10(11.4)$ \\
\hline No & $78(88.6)$ \\
\hline Pneumonia & \\
\hline Yes & $3(3.4)$ \\
\hline No & $85(96.6)$ \\
\hline Sepsis & $0(0.0)$ \\
\hline Yes & $88(100.0)$ \\
\hline No & $0(0.0)$ \\
\hline Steroid use & $88(100.0)$ \\
\hline Yes & \\
\hline No & \\
\hline
\end{tabular}

$\mathrm{NB}=$ No prior history of cryptococcosis and no meningism among the subjects Table 2: Some risk factors for Cryptococcosis in the cohort.

routine screening for $\mathrm{Cr} \mathrm{Ag}$.

Generally, epidemiology data suggest that cryptococcosis is uncommon in HIV-infected children. Gonzalez et al. reported an 8 -year point prevalence of $0.85 \%$ in the USA [10]. Abadi et al. [16], also in the USA, reported a 10-year point prevalence of $\sim 1 \%$. In Zimbabwe, Gumbo et al. [9] reported a prevalence of $1.4 \%$. However, in Thailand, $2.97 \%$ point prevalence was observed during an eight-year study among hospitalized HIV-infected patients [20]. In South Africa, the incidence of cryptococcosis among HIV-positive children was 47 cases per 100,000 persons [11].

Despite the substantive risk factors (i.e. farming, tuberculosis, etc.) that the children in the present study were exposed to, we do not know why cryptococcal antigenaemia was not found among our cohort with a very low $\mathrm{CD} 4$ count.

Others $[16,21]$ have suggested that children with HIV infection acquired via vertical transmission (a major finding in our study, 82 subjects, 93.2\%) may be less likely to develop cryptococcosis, underscoring the risk of cryptococcosis transmission via blood transfusions $[9,16,20,22]$.

Although, a majority (69 subjects, 78.4\%) of our cohorts engaged in farming (avian excreta, vegetables, fruits, and dairy products are potential sources of cryptococcosis [12]), yet we did not find cryptococcal antigenaemia in our cohort. Goldman et al. [22] had also demonstrated that the low incidence of symptomatic cryptococcal disease in children with AIDS is not as a result of lack of exposure, as they often did, once they have learnt to walk.

Furthermore, the ART which our children have been taking may not readily explain the $0 \%$ prevalence of $\mathrm{Cr} \mathrm{Ag}$ as studies in adult population have reported a high prevalence of $\mathrm{Cr} \mathrm{Ag}$ even among patients on ART [23,24].

However, the difference in the clinical course of HIV infection in children has been postulated as a reason why cryptococcosis and other OIs including toxoplasmosis, cytomegalovirus (CMV) infections, and Kaposi's sarcoma, are less frequent in children than in adults $[8,25]$.

Meya et al. [26] had estimated the cost-benefit analysis of preventing one death through $\mathrm{Cr} \mathrm{Ag}$ screening (and fluconazole treatment) to be $\$ 266$ in an Ugandan cohort with a prevalence of asymptomatic antigenaemia of $13.5 \%$ and $\$ 500$ once the prevalence of 'asymptomatic' antigenaemia falls below $5 \%$. Although, their analysis was done in adult population, it definitely may not be cost effective to embark on routine screening for $\mathrm{Cr} \mathrm{Ag}$ in our paediatric setting with no cryptococcal antigenaemia.

Our study is limited by the fact that it was done in a tertiary hospital setting and the generalization of the findings may not be plausible.

Also, our study was among children seen over a period of 9 months and as such the findings may not be too comparable with earlier studies in children $[9-11,16,20]$.

In addition, as mentioned earlier in the methodology, the use of plasma for $\mathrm{Cr} \mathrm{Ag}$ in our study has limited the sensitivity of the $\mathrm{Cr} \mathrm{Ag}$ LF assay to $98.9 \%$.

Furthermore, a survival bias may also have limited the generalization of our study as many of our HIV-infected children with advanced disease and possible cryptococcal antigenaemia may have died before recruitment into our care and treatment program.

In conclusion, the $0 \%$ prevalence of $\mathrm{Cr} \mathrm{Ag}$ in our setting has made cryptococcosis a weak contender in the differential diagnosis of severely immunosuppressed HIV-infected children ( $\leq 15$ years) presenting with pneumonia and or meningoencephalitis.

\section{Acknowledgements}

The Authors would like to acknowledge and thank all the patients and staff of the APIN/Harvard PEPFAR program at the Federal Medical Centre, Makurdi, Benue State, Nigeria. Special thanks also go to the Mustard-Seed Children's Specialist Hospital, Makurdi, Benue State for providing the $\mathrm{Cr} \mathrm{Ag}$ Lateral Flow Kits used for this study.

\section{References}

1. Park BJ, Wannemuehler KA, Marston BJ, Govender N, Pappas PG, et al (2009) Estimation of the current global burden of cryptococcal meningitis among persons living with HIVIAIDS. AIDS 23: 525-530.

2. World Health Organization (2011) Rapid Advice. Diagnosis, Prevention and Management of Cryptococcal Disease in HIV-infected Adults, Adolescents and Children.

3. Lessells RJ, Mutevedzi PC, Heller T, Newell ML (2011) Poor long-term outcomes for cryptococcal meningitis in rural South Africa. S Afr Med J 101: 251-252.

4. Bicanic T, Meintjes G, Wood R, Hayes M, Rebe K, et al. (2007) Fungal burden, early fungicidal activity, and outcome in cryptococcal meningitis in an antiretroviral naïve or antiretroviral experienced patients treated with amphotericin B or fluconazole. Clin Infect Dis 45: 76-80. 
Citation: Anígilájé EA, Olutola A, Dabit O, Adeoti AO, Emebolu AJ, et al. (2013) There is No Cryptococcal Antigenaemia among A Cohort of Children with Advanced HIV Infection in an Antiretroviral Therapy Programme in Makurdi, Nigeria. J AIDS Clin Res 4: 261. doi: 10.4172/2155-6113.1000261

5. Kambugu A, Meya DB, Rhein J, O'Brien M, Janoff EN, et al. (2008) Outcomes of cryptococcal meningitis in Uganda before and after the availability of highly active antiretroviral therapy. Clin Infect Dis 46: 1694-1701.

6. Mitchell TG, Perfect JR (1995) Cryptococcosis in the era of AIDS--100 years after the discovery of Cryptococcus neoformans. Clin Microbiol Rev 8: 515-548.

7. Perfect JR (1989) Cryptococcosis. Infect Dis Clin North Am 3: 77-102.

8. Nicholas SW (1994) The opportunistic and bacterial infections associated with pediatric human immunodeficiency virus disease. Acta Paediatr Suppl 400: 46-50.

9. Gumbo T, Kadzirange G, Mielke J, Gangaidzo IT, Hakim JG (2002) Cryptococcus neoformans meningoencephalitis in African children with acquired immunodeficiency syndrome. Pediatr Infect Dis J 21: 54-56.

10. Gonzalez CE, Shetty D, Lewis LL, Mueller BU, Pizzo PA, et al. (1996) Cryptococcosis in human immunodeficiency virus-infected children. Pediatr Infect Dis J 15: 796-800.

11. Meiring ST, Quan VC, Cohen C, Dawood H, Karstaedt AS, et al. (2012) A comparison of cases of paediatric-onset and adult-onset cryptococcosis detected through population-based surveillance, 2005-2007. AIDS 26: 2307-2314.

12. Aberg JA, Powderly WG (2006) Cryptococcosis and HIV. HIV In Site Knowledge Base Chapter.

13. van der Horst CM, Saag MS, Cloud GA, Hamill RJ, Graybill JR, et al. (1997) Treatment of cryptococcal meningitis associated with the Acquired Immunodeficiency Syndrome. National Institute of Allergy and Infectious diseases. Mycoses Study Group and AIDS Clinical Trial Group. N Eng J Med 337: 15-21.

14. French N, Gray K, Watera C, Nakiyingi J, Lugada E, et al. (2002) Cryptococcal infection in a cohort of HIV-1-infected Ugandan adults. AIDS 16: 1031-1038.

15. Jarvis JN, Lawn SD, Vogt M, Bangani N, Wood R, et al. (2009) Screening for cryptococcal antigenemia in patients accessing an antiretroviral treatment program in South Africa. Clin Infect Dis 48: 856-862.
16. Abadi J, Nachman S, Kressel AB, Pirofski L (1999) Cryptococcosis in children with AIDS. Clin Infect Dis 28: 309-313.

17. Mamoojee Y, Shakoor S, Gorton RL, Sarfo S, Appiah LT, et al. (2011) Short Communication: Low seroprevalence of cryptococcal antigenaemia in patients with advanced HIV infection enrolling in an antiretroviral programme in Ghana. Trop Med Int Health 16: 53-56.

18. Alemu AS, Kempker RR, Tenna A, Smitson C, Berhe N, et al. (2013) High prevalence of Cryptococcal antigenemia among HIV-infected patients receiving antiretroviral therapy in Ethiopia. PLoS One 8: e58377.

19. Cryptococcal antigen Lateral Flow kit. Immuno-Mycologics Inc., 2700 Technology Place, Norman OK 73071, USA. Reference CR2003, Lot 012CR2. Pamphlet on summary and procedure.

20. Likasitwattanakul S, Poneprasert B, Sirisanthana V (2004) Cryptococcosis in HIV-infected children. Southeast Asian J Trop Med Public Health 35: 935-939.

21. Leggiadro RJ, Kline MW, Hughes WT (1991) Extrapulmonary cryptococcosis in children with acquired immunodeficiency syndrome. Pediatr Infect Dis J 10 658-662.

22. Goldman DL, Khine H, Abadi J, Lindenberg DJ, Pirofski La, et al. (2001) Serologic evidence for Cryptococcus neoformans infection in early childhood. Pediatrics 107: E66.

23. Jarvis JN, Boulle A, Loyse A, Bicanic T, Rebe K, et al. (2009) High ongoing burden of cryptococcal disease in Africa despite antiretroviral roll out. AIDS 23 1182-1183.

24. National Institute for Communicable Diseases (2012) GERMS-SA Annua Report 2011, Johannesburg: National Institute for Communicable Diseases.

25. Wiznia AA, Lambert G, Pavlakis S (1996) Pediatric HIV infection. Med Clin North Am 80: 1309-1336.

26. Meya DB, Manabe YC, Castelnuovo B, Cook BA, Elbireer AM, et al. (2010) Cost-effectiveness of serum cryptococcal antigen screening to prevent deaths among HIV-infected persons with a CD4+ cell count $<$ or $=100 \mathrm{cells} / \mathrm{microL}$ who start HIV therapy in resource-limited settings. Clin Infect Dis 51: 448-455. 